\title{
Radioactivity of the lower sector of Danube River and the Black Sea coastal zone in relation to some hydrological characteristics
}

\author{
Constantin Borcia, Carmen Rădulescu, Radu Ciucă, Viorel Blendea
}

\begin{abstract}
On ecosystems, the radioactive material can have several consequences: the mechanisms of self-regulation of biocoenosis are affected; the interactions and composition of flora and fauna in biocoenosis are modified etc., and on humans, radioactive material presents a major risk through external exposure and internal exposure to radiation. On the other hand, floods and droughts, among others, can have the effect that they can act as a support for radionuclides. The existence of risks of radioactive and chemical pollution on the lower course of the Danube, in the Black Sea Danube spill area as well as in the Black Sea coastal area, where a number of complex processes occur, determined the study of the radiochemical processes taking place in these areas.

The paper addresses the following issues: radiation risk and nuclear risk, general hydrological characteristics, radioactivity of the Lower Danube water and coastal zone of the Black Sea, radioactivity of the Lower Danube sediments and coastal zone of the Black Sea, modeling of radiochemical processes.
\end{abstract}

Keywords -radioactivity, hydrological parameters, variability, modeling, nuclear risk.

\section{INTRODUCTION}

There is an indirect link between floods and / or droughts and the radioactivity of the environment, in the case of floods, large amounts of water spilled from riverbeds or rivers may also contain various radionuclides present in water, which can be deposited in flooded areas. Subsequently, they can enter the trophic circuit and can be irradiation sources with unpredictable effects on biocenoses and humans. In the case of droughts, a

\footnotetext{
Manuscript received $4^{\text {th }}$ June 2017

Constantin Borcia, Carmen Rădulescu, Radu Ciucă, Viorel Blendea - National Institute of Hydrology
} 
series of radionuclides can be deposited from the atmosphere on the surfaces of the soils and the broken parts of the bed, initiating the accumulation process. Later on, during floods, they can be taken over by the masses of water, they can enter the trophic circuit, and the effects will be unpredictable. So, floods, and droughts, can, among other things, have the potential to act as a support for radionuclide action.

\section{RISK OF IRRADIAS AND NUCLEAR RISK}

The danger is the risk of irradiation.

- Risk of irradiation: is the probability of occurrence of human or material lesions or losses in a reference period and in a given area by a nuclear event, $\mathrm{Ri}=\mathrm{Pi} \mathrm{x}$ $\mathrm{Ci}$ (1) where $\mathrm{Pi}$ - the probability Producing any event; But - the harmful effect of a nuclear accident.

- Collateral risks: is the probability of producing events that can induce, contribute, or favor through a produced nuclear event, $\mathrm{Rc}=\mathrm{Pc} \times \mathrm{Ri}(2)$ where: $\mathrm{Pc}$ the probability of occurrence of an event that could cause a nuclear accident.

Nuclear risk is a generalization of irradiation risk, representing the total probability of producing a nuclear event with harmful or fatal effects on humans and generally on biocenoses.

Nuclear risk control can be done, on the one hand, by: predictive monitoring and monitoring of the sources of radioactive pollution of the environment, by the creation of data banks and model banks, by the creation of warning systems and by collateral studies (hazard analysis, risk management). On the other hand, the information provided by these studies is used in a decision-making system to intervene in the event of a nuclear accident. Furthermore, the purification, respectively the methods and techniques of depollution (purification, decontamination, detoxification), which are added to the natural purification processes (self-purification or self-purification), apply after the decisions.

A "feed-back" feedback loop is created, controlling the nuclear risk, in other words reducing the likelihood of accidental radioactive pollution and generally pollution of any kind. In fig. 5 for example, a simplified scheme for regulating nuclear risk is presented through decision components and purification components. A general scheme of nuclear risk control is given in Figure 1.

The existence of risks of radioactive and chemical pollution on the lower course of the Danube, in the Black Sea Danube spill area as well as in the Black Sea coastal area, where a number of complex processes occur, determined the study of the radiochemical processes taking place in these areas. The years and stages concerned with the Danube radioactivity study, the Romanian sector, are summarized as follows (synthesis made subject to the limitations of the information sources) (BORCIA C.M., BĂTUCĂ D, GH. 2002):

- 1957 - He began the study of the Danube's radioactivity, the upper and the middle course.

- 1962 - He began the study of Danube radioactivity, the Romanian sector.

- 1974 - CNE - KOZLODUI 1 was put into use. 


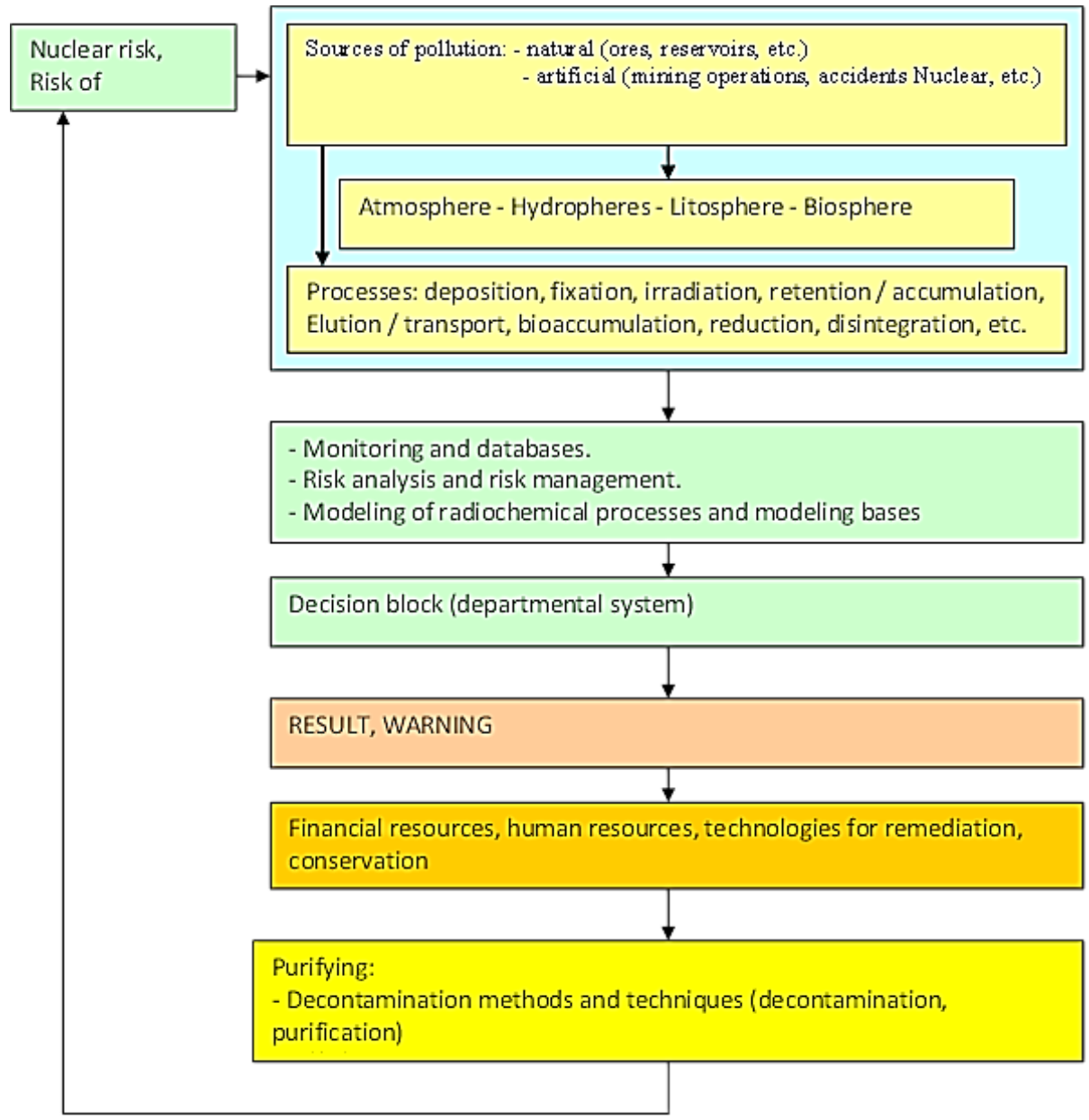

Fig. 1 Simplified scheme for regulating nuclear risk through monitoring components, decision components and purification components

- 1976, 1977 - In the summer of these years, two expeditions were conducted on the Romanian Danube sector between Tulcea and Moldova Veche for studying the radioactivity of water, sediments and hydrobonds.

- 1978 - The scientific expedition for studying the radioactivity of the Danube River, between Sulina and Bratislava, took place between 24 August and 24 September.

- 1986 - The Chernobyl accident occurred on April 26th.

- 1986-1988 - Water and sediment samples collection in different hydrometric sections.

-1991-1996 - Biannual expedition campaigns with samples of water and sediment, between Baziaş and the mouths of the Danube.

- 1996 - CNE - CERNAVODA 1 became operational. 
- 1997 - Expeditionary campaign with samples of water and sediment, between Bazias and the mouths of the Danube.

- 1998 - Water and sediment extraction from Baziaş and Ceatal Izmail.

- 1999 - 2003 - Specimen harvesting of samples.

Among the sources of radioactive contamination of the Danube River, over time, one can remember:

- nuclear tests, by 1980 ;

- accidentull from Chernobyl on 26 April 1986;

Currently, sources of radioactive contamination include:

- Upper and middle course NCE CNE from Kozloduy - Bulgaria; CNE from Cernavoda - Romania; (However, it should be noted that these sources are in fact potential contamination sources, which can become major sources of contamination in the event of accidents)

- Various mining and industrial activities located on the Danube tributaries (uranium, carboniferous mining, etc.).

- On the lower Danube, areas with nuclear risk are: Dolj county and some of the counties of Olt, Gorj and Mehedinti, due to Kozloduy NPP; The Constanta, Ialomita and Calarasi counties due to Cernavoda NPP.

- In the case of the Black Sea coastal zone, the nuclear risk is constituted by a complex of natural and artificial factors, including the indirect contamination caused by the transport of radioactive pollutants by the rivers flowing into the Black Sea or due to the radioactive deposits in the case Nuclear accidents or nuclear tests, correlated with atmospheric traffic and sea currents; The transport of radioactive material by sea and / or river and the possibility of accidents, etc.

\section{SYSTEMIZATION OF THE RADIOCHEMICAL AND HYDROLOGICAL FUND}

The information sources and the data base (applied to the lower Danube sector including the Transition Area - Sheds - and the Black Sea coastal area) are diverse, for example:

- Hydrological synthesis studies including radiochemical, hydrological data and qualitative indicators of Danube water and sediments, the Danube Delta and the Black Sea coastal area.

- Determinations - sampling of water and sediments carried out as a result of biannual expedition campaigns on the Danube, the Danube Delta and the Black Sea coastal area in the period 1991-1997, followed by laboratory measurements and measurements, on the beta-global activity Water and sediment, sediment chemistry, sediment radioactivity (some radionuclides present in sediments). 


\section{VARIABILITY OF HYDROLOGICAL PARAMETERS}

It is important to observe the variability of maximum and minimum water flows as well as the variability of the suspended solids flows because, as stated, there is an indirect link between floods and / or drought and the radioactivity of the environment. As a result, it is useful to outline some aspects of this variability.

\section{Variability of minimum water flows}

As it is known, drought is the prolonged absence or lack of precipitation, the hydrological drought is defined as an abnormally dry period of time, sufficiently prolonged to draw a water shortage characterized by a significant drop in water leakage, of levels in lakes and / or underground drains, bringing them below normal values and / or abnormal soil drying. Drought has several stages of evolution: atmospheric drought (decrease in soil moisture), soil drought (significant soil drying and low water level) and hydrological drought (when deep water levels decrease significantly and a reduction in river flow). Analyzing the statistics, it was established that the warmest years were 1998, 2001, 2002, 2003 and 2004. The lack of precipitation caused Romania to face the prolonged drought phenomenon at such intervals as: 1894-1907, 1945-1951, $1983 \quad-1994, \quad 2000-2003$ (http://stiri.rol.ro/content/view/61129/3/).

Between 1961-2010, small and very small flows were recorded at the hydrometric stations on the Danube, indicating droughts.

The lowest annual water flows (minimum minimum) are shown in Figure 2.

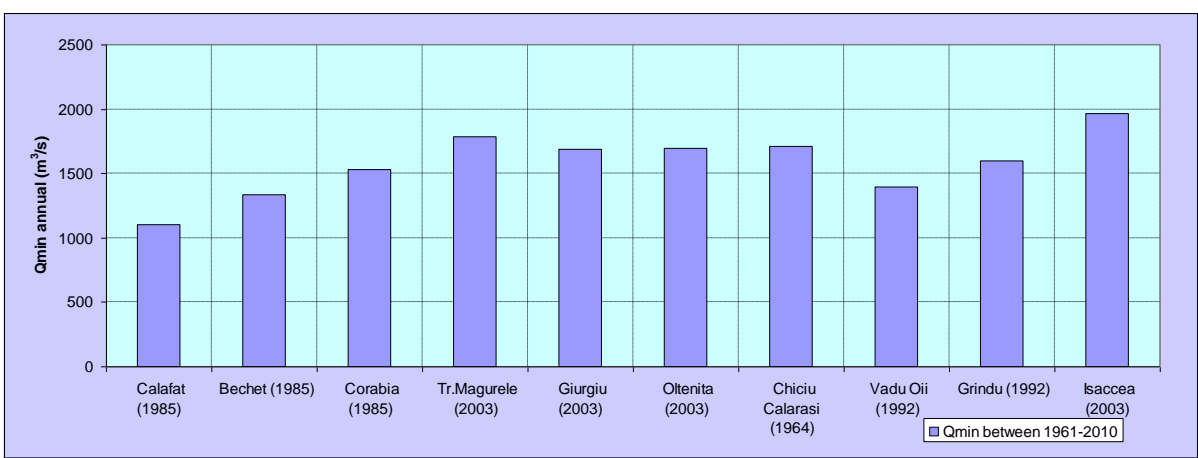

Fig. 2 Minimum minimum water flows (minimum minimum) recorded at hydrometric stations on the Danube between 1961-2010

\section{Variability of maximum water flows}

As is known, floods have several causes, including: natural phenomena (overflowing water, precipitation or snow melting, stagnant or drifting on the slopes, raising groundwater over the ground due to infiltration, marine storms ) Accidental phenomena (breakage or damaging of dams or other hydrotechnical constructions, wrong maneuvers at the evacuators of the accumulations, sudden sliding of the slopes in the reservoir reservoir); Human activities (filling of the artificial vase, intentional 
cutting of the dykes, realization of irrigation systems with large losses of water without adequate drainage measures, floods caused by earthquakes induced by accumulations). Among the significant floods produced on the Danube can be mentioned the ones produced in the years: 1895, 1926, 1942, 1970, 1975, 1981, 2006.

Between 1961-2010, the hydrometric stations on the Danube have recorded large and very high flows, which signal the floods. The highest annual water flows (maximum maximum) are shown in Figure 3.

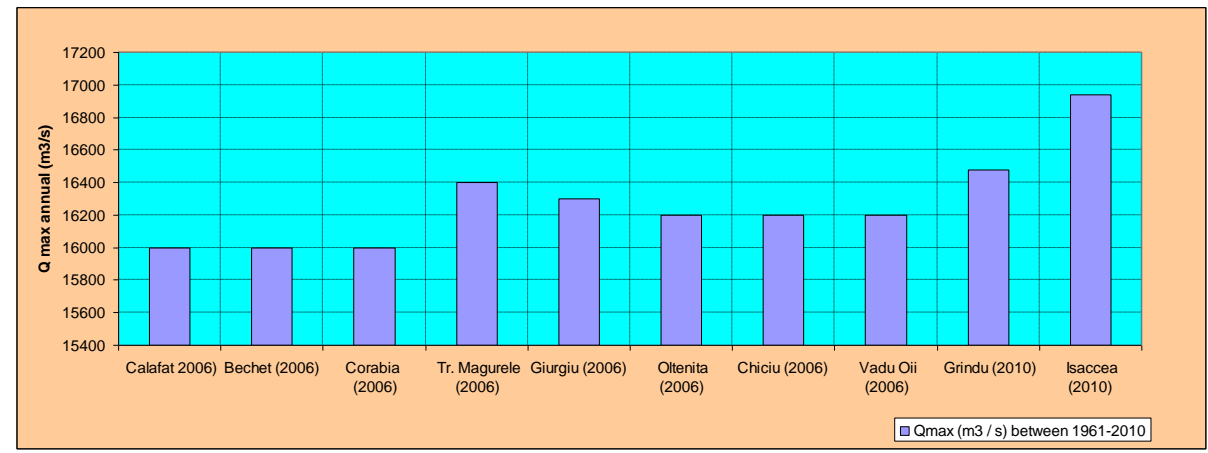

Fig. 3 The highest maximum water flows (maximum maximum) recorded at hydrometric stations on the Danube between 1961-2010

In general, the existence of maximum water flows equal to or greater than $14000 \mathrm{~m} 3$ / s may indicate the existence of floods.

\section{Variability of suspended particulate matter flows}

For a time span between 1931-2010, the variation of the slurry flow rates (annual average values) is shown in Figure 4.

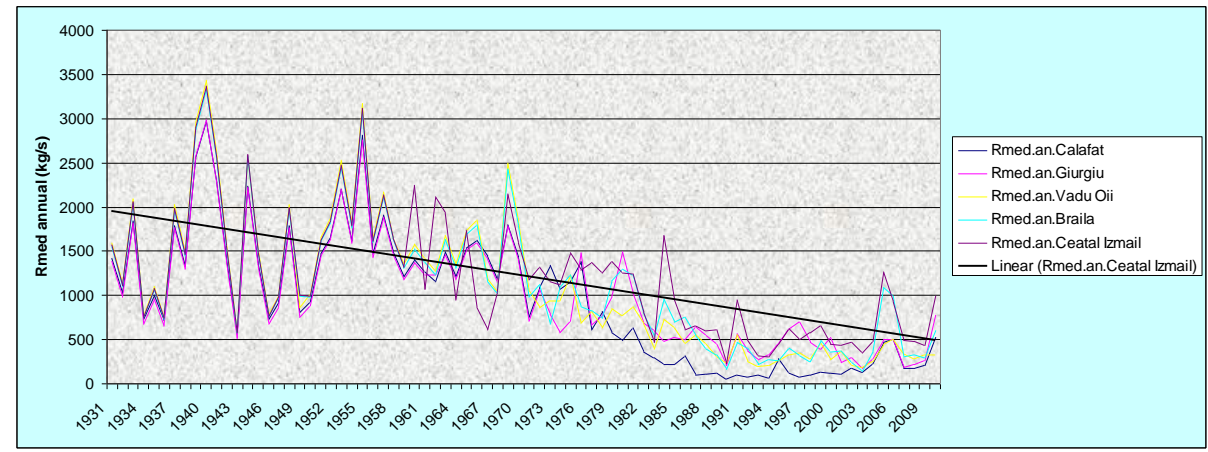

Fig. 4 Variation of annual average suspended sludge flows in the period 1931-2010 at characteristic hydrometric stations on the Danube River (Rmed-medium alluvial flow rate)

The figure shows that there is generally a downward trend in average annual slurry feed rates. 


\section{Variability of marine levels}

Sea levels have a oscillatory change over time under the influence of hydrological, meteorological and cosmic factors. In general, the background of the temporal variation of sea levels (annual and monthly averages), follows the temporal variation of the annual and monthly average water flows flowing from the Danube into the Black Sea. This characteristic is due to the fact that the share of Danube in the water supply in the water balance of the Black Sea basin exceeds 6\%, having a major role in regulating the Black Sea hydrological regime. As a result, there is a close link between the annual average values of Danube water flow rates and the water levels of the Black Sea.

Based on the observations data and the direct measurements on the levels, there were significant short-term variations (daily and hourly) of the Black Sea levels. Due to the intense winds operating from the sea, or from the dry land, the deviations of the sea water mirror reach values of $\pm 60 \mathrm{~cm}$, with an average frequency of once every 3 years in the coastal area of the Danube Delta.

\section{RADIOACTIVITY OF WATER DANUBE WATER AND COASTAL ZONE OF BLACK SEA}

In the case of water, specific beta-global activity was determined. It represents the sum of beta (electron) emission of all nuclei of unstable isotopes in water, with a random character. In the expeditionary campaigns water samples were taken that were analyzed globally. The results of the processing were statistically processed. The average beta-global average activity in water in the 1992-1997 expedition campaigns is shown in Figure 5.

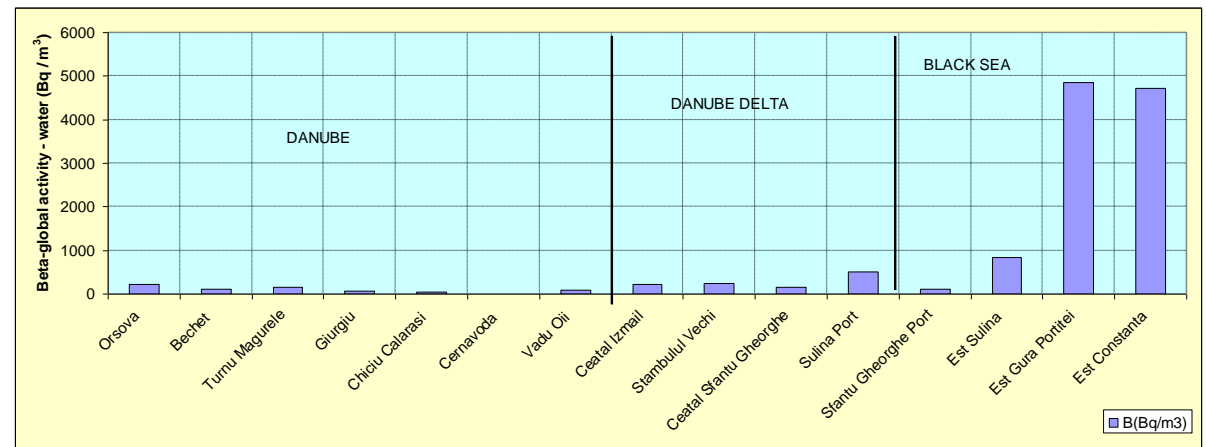

Fig. 5 Variability of beta-global specific activity indicator in water (mean values)

We can see the distribution of the average activity in the case of the Danube - in the Orşova area, its decrease over the time to Ceatal Izmail where it grows, then it decreases inside the Delta and grows again in the area of the transitional waters and then there is a significant increase in the coastal zone (Gura Portiţei and Constanţa). The explanation of these findings is complex. In the coastal zone, the increase in beta 
- global activity is due, among other things, to the following fact. Some of the radionuclides (which have beta emission) come from the fallout. The higher the deposition area, the higher the amount of radionuclide and therefore the beta-globe concentration and activity, respectively. In the marine area there are large deposition areas and hence increased activity, which was also found. In the case of river and delta, the situation is more complex and several factors have to be taken into account the chemical composition and composition and particle size of the suspensions specific to each area and resulting in the replay of the specific activity presented.

\section{THE RADIOACTIVITY OF THE LOWER DANUBE SANDMENTS AND THE BLACK SEA COASTAL ZONE}

In the case of sediments, the specific beta activity was determined and the specific activity of some radionuclides (ie gamma - global activity). Radionuclides highlighted were: Cs-137; K-40; U-238; Th-232; As well as sporadically Cs-134; R226; Ra-228. The natural radionuclides (U-238; Th-232; K-40) come from various rocks (limestone, dolomite, sandstone, shale, marl) Uranium, along with other radioactive elements, from various economic, research or military activities.

Figure 6 and Figure 7 shows the variability of beta-global specific activity and gamma gamma gamma activity variability of Cs-137, U-238, Th-232, and K-40 radionuclides respectively.

Figures show a certain distribution of specific beta-global activity in the sediment, due to the types of beta-ion radionuclides on the one hand, and on the other hand the chemical nature of the sediment as well as the granulometric structure his; On the other hand, it is noticed that the gamma activity is increased in the area of the Danube (Sviniţa, Orşova, Țigănaşi), decreases along the way, then increases in the Delta area (the mouths) and in the Black Sea coastal zone. The explanation for this behavior is the granulometric structure and the chemical composition of the sediment in those areas.

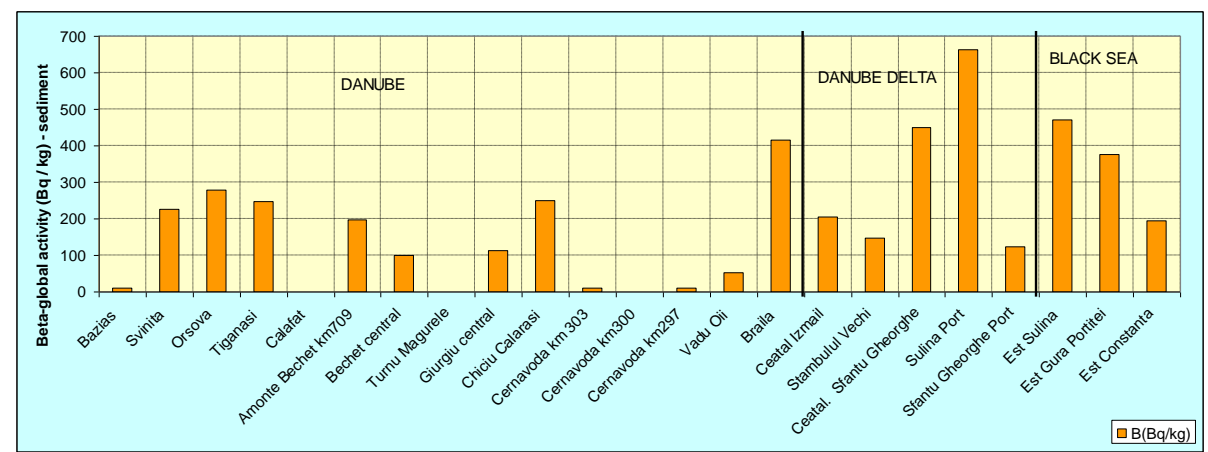

Fig. 6 Variability of beta - global specific activity indicator in sediment (mean values) 


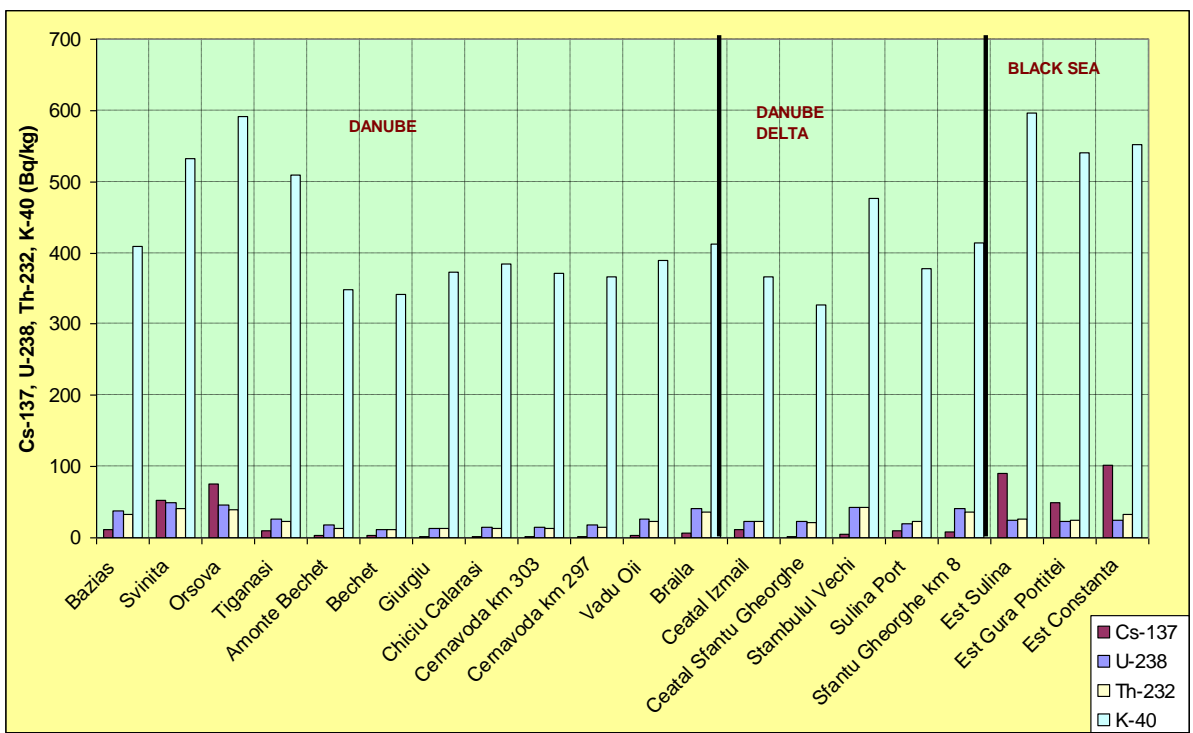

Fig. 7 Variability of gamma medium activity of radionuclides Cs-137, U-238, Th232, K-40

Chemical determinations have also shown that together with unstable isotopes (i.e., radionuclides) there are the following compounds (oxides): $\mathrm{SiO} 2$ (major chemical compound); $\mathrm{Al} 2 \mathrm{O} 3$; As a; Fe2O3; Na2O; K2O; MgO; TiO2; MnO; P2O5; (Minor chemical compounds), as well as loss of calcination (P.C.), or organic material. These chemical compounds have various origins, such as: light minerals (quartz, opal, chalcedony, feldspar, etc.); Heavy minerals (amphibols, granates, pyroxenes, rutile, etc.); Clay minerals (kaolinite, illit, etc.); bioclastic; various agroindustrial activities. Loss of calcination or organic material comes from scraps of organisms, spores, agro-industrial activities.

There is a certain relationship between the percentage chemical composition and the specific activity of radionuclides. In the case of river sediments and marine sediments, it is found that where the percentage of chemical composition of $\mathrm{SiO} 2$ is lower, the specific activity of radionuclides is higher and higher, and also where the chemical composition of chemical compounds Minorities and organic material is higher.

In order to quantify this, the average radiochemical factor $(\mathrm{F})(\mathrm{Bq} / \mathrm{kg} \%$ chemical compound) (Borcia, 2004) of a radionuclide in a given chemical compound is calculated. As an example, the average radiochemical accumulation factors of Cs137 in $\mathrm{SiO} 2, \mathrm{CaO}, \mathrm{Al} 2 \mathrm{O} 3$ and P.C. (Organic material) for several sections.

These findings lead to the following hypothesis on the radionuclide distribution shown in Fig. Minor chemical compounds (Al2O3; CaO; Fe2O3; Na2O; K2O; MgO; $\mathrm{TiO} 2 ; \mathrm{MnO})$ are included in minerals such as feldspars, zeolites, etc. Zeolites - a category of zeolite is for example $\mathrm{Na} 2$ [A12Si3O10] $(\mathrm{H} 2 \mathrm{O}) 2$ - have a complex ionic 
crystal structure, and these crystalline structures possess selective adsorption property. The porous structure of the zeolites allows rapid migration of ions into and out of the zeolite; Zeolites behave as ion exchangers, who in turn results in the retention of radionuclides in their crystalline network; But since exchange reactions are reversible, this retention is not permanent. On the other hand, the crystalline $\mathrm{SiO} 2$ network is more compact and does not allow the retention of ions (radionuclides) in the crystalline network. Causes of radionuclide retention predominantly in minority compounds are directly related to the mineralogical structure, respectively, to the crystallisation systems of the minerals and sediment-forming rock, the interstitial spaces and the crystalline networks, the elution-retention and ion exchange processes

Table 1 Average radiochemical storage factors (example)

\begin{tabular}{|l|c|c|c|c|c|c|}
\hline $\begin{array}{l}\text { Accumulati } \\
\text { on factor } \\
\mathrm{F}\end{array}$ & $\begin{array}{l}\mathrm{F}(\mathrm{Cs}-137 / \\
\left.\mathrm{SiO}_{2}\right) \\
(\mathrm{Bq} / \mathrm{kg} \%)\end{array}$ & $\begin{array}{l}\mathrm{F}(\mathrm{Cs}-137 / \\
\mathrm{CaO}) \\
(\mathrm{Bq} / \mathrm{kg} \%)\end{array}$ & $\begin{array}{l}\mathrm{F}(\mathrm{Cs}-137 / \\
\left.\mathrm{Al}_{2} \mathrm{O}_{3}\right) \\
(\mathrm{Bq} / \mathrm{kg} \%)\end{array}$ & $\begin{array}{l}\mathrm{F}(\mathrm{Cs}-137 / \\
\left.\mathrm{Na}_{2} \mathrm{O}\right) \\
(\mathrm{Bq} / \mathrm{kg} \%)\end{array}$ & $\begin{array}{l}\mathrm{F}(\mathrm{Cs}-137 / \\
\left.\mathrm{K}_{2} \mathrm{O}\right) \\
(\mathrm{Bq} / \mathrm{kg} \%)\end{array}$ & $\begin{array}{l}\mathrm{F}(\mathrm{Cs}-137 / \\
\mathrm{P} . \mathrm{C} .) \\
(\mathrm{Bq} / \mathrm{kg} \%)\end{array}$ \\
\hline $\begin{array}{l}\text { Svinita } \\
\text { (Danube) }\end{array}$ & 1,14 & 4,05 & 3,53 & 28,57 & 37,81 & 4,26 \\
\hline $\begin{array}{l}\text { Giurgiu } \\
\text { (Danube) }\end{array}$ & 0,02 & 1,11 & 0,96 & 0,91 & 1,10 & 0,86 \\
\hline $\begin{array}{l}\text { Ceatal } \\
\text { Izmail } \\
\text { (Danube) }\end{array}$ & 0,16 & 2,41 & 2,14 & 4,86 & 6,84 & 2,01 \\
\hline $\begin{array}{l}\text { Ceatal Sf. } \\
\text { Gheorghe } \\
\text { (Danube } \\
\text { Delta) }\end{array}$ & 0,03 & 0,38 & 0,57 & 1,26 & 1,53 & 0,347 \\
\hline $\begin{array}{l}\text { Est } \\
\text { Constanta } \\
\text { (Black Sea) }\end{array}$ & 1,63 & 11,92 & 13,35 & 47,24 & 65,95 & 12,22 \\
\hline
\end{tabular}

\section{MODELING OF RADIO-CHEMICAL PROCESSES}

In the case of the Danube and the coastal zone of the Black Sea, the modeling of the radiochemical processes is complicated and involves the following general requirements (Borcia, 2004).

- In order to achieve a radiochemical model applicable to the Lower Danube, it should contain several modules, including: a GIS / GRID / BATIM module (locating programs, grid patterning and bathymetry), a CLIMATOLOGICO HYDROCHIMICAL-FLUVIAL HYDROCHIMIC (programs for describing and calculating important factors such as: flow velocity, turbulence, sedimentation, evaporation, wind and precipitation dynamics, etc.), a HYDROCHIMIC- 
ECOLOGICAL FLUVIAL module (programs required for description and calculation Parameters such as temperature, mineralization, concentration of some ions, suspensions, chemical indicators, light flux, density of organisms, etc.) and a RADIOCHIMIC FLUVIAL module (programs for the calculation of some parameters such as diffusion, sorption, adsorption, concentration radionuclides.

In order to achieve a simplified model of transport and transfer of radionuclides in the Black Sea coastal zone, it is possible to consider as a minimum the costing of four component modules of this model: a GIS / GRID / BATIM module - for realizing the spatial network, Batimetry, then a marine climatic-hydrodynamic module - for the calculation of some marine parameters (solar radiation, evaporation, speed field, pressure field), a hydrochemical-ecological module - for calculating some hydochimic parameters (temperatures, salinity, dissolved salts, H, dissolved oxygen) and some ecological parameters (chlorophyll, phytoplankton, etc.) and a radiochemical module for the description of some radiochemical parameters (radionuclide concentration, diffusion, sorption). To these should also be added the edge conditions (for the north, east, south directions) as well as a program for the implementation of the monitoring data.

Figure 8 gives a general outline of the modeling of fluvial / marine radiochemical processes.

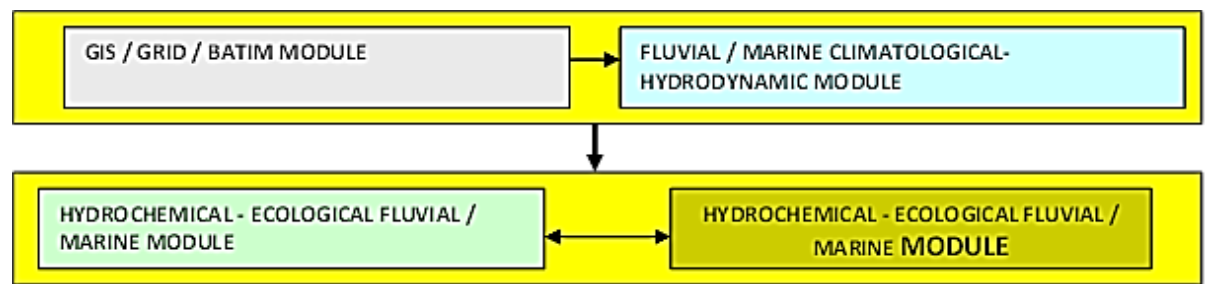

Fig. 8 Basic scheme of the simplest model of transport and transfer of radionuclides in the river / marine aquatic environment

The realization of such a numerical model is in the current stage quite difficult and requires large investments, both human and financial.

\section{CONCLUSIONS}

- Floods, droughts, can also have other consequences and that they can act as support for radionuclides. This is due to the presence in the water of various radionuclides that can be deposited in flooded areas and can later enter a trophic circuit; On the other hand, in case of drought, radionuclides from fall out can accumulate on the surfaces of the soils or parts of the drybed.

- Among the sources of radioactive contamination of the Danube and the coastal zone of the Black Sea are: Higher and Medium Higher Education Centers; CNE from Kozloduy - Bulgaria; CNE from Cernavoda - Romania; (These can become major 
sources of contamination in case of accidents) various mining and industrial activities located on the Danube tributaries (uranium, carboniferous mining exploitations, etc.); Indirect contamination due to the transport of radioactive pollutants by rivers flowing into the Black Sea or due to radioactive deposits in nuclear accidents or nuclear tests, correlated with atmospheric traffic and sea currents; The transport of radioactive material by sea and / or river and the possibility of accidents, etc.

- The variability of the Danube and the Black Sea coastal radioactivity is due to a complex of factors, being generally a consequence on the one hand of the hydrogeological processes and, on the other hand, of the natural radiochemical processes.

- There are ways of modeling the radiochemical processes taking place in the Danube River and in the Black Sea coastal zone, the yarmodels that can be elaborated are interdependent and very complex.

- Nuclear risk control is a complicated process that can be modeled by a feedback circuit, which includes: monitoring and risk monitoring components, decision making components (social-political-economic-ecological) And purifying components (depollution, purification, sanitation, etc. combined with natural purification processes).

\section{ACKNOWLEDGMENTS}

Thanks Mrs. Prof. Dr. Carmen Maftei for support.

\section{REFERENCES}

[1] BORCIA C.M., BĂTUCĂ D, GH. 2002. Radioactive pollution hazard of the Danube River along the Romanian reach", $21{ }^{\text {st }}$ Conference of the Danube countries. [2] BORCIA C.M., ALEXIU GH.,F, GEORGESCU I.I., TEODOR R.,S., 2002 . Aspects concerning certain radio-chemical characteristics of the lower danube sediments, Comunicare, $21{ }^{\text {st }}$ Conference of the Danube countries.

[3] BORCIA, C. 2004. Modelarea matematică a proceselor radiochimice în funcţie de regimul hidrologic al sedimentelor dintr-un anumit sector al fluviului Dunărea", Teza doctorat, UPB.

[4] BORCIA, C., Roxana BOJARIU, et all - "Evidence of climatic and hydrological hazards in Danube region and over Romanian confluence areas for Danube tributaries", INHGA - International Scientific Conference / Conferința Științifică Internațională a INHGA "Hydrological Hazards and Associated Risks Management"/ "Hazarduri hidrologice și managementul riscurilor asociate", Bucharest, October 810, 2012 / București, 8 - 10 octombrie

[5] BORCIA,C., Sorin TEODOR., S., Carmen RADUlESCU, Carmen PETREA, CIUCA., R, BLENDEA., V, - "Aspects of variability of hydrological parameters as a result of human impact and climate change if the lower Danube" ,Conferinţa ştiinţifică a INHGA / INHGA - Scientific Conference, Bucureşti, 10 - 11 noiembrie 2014 / Bucharest, November 10-11, 2014 
[6] OPRICA, M.H.I., GEORGESCU, I.I., BORCIA, C.M. , 2001 On a mathematical model transport and transfer of the radionuclides in Danube river, Romanian sector, Rapp.Comm. int. Mer. Medit., 36.

[7] GEORGESCU. I IULIA, PANTELICA ANA, SALAGEAN. MARIA, 1977 Natural and artificial radioactivity of bed load sediments of Danube and Black Sea during 1994-1995, Proceedings Supplements of balkan physics letters, volume 5.

[8] MARINGER F.J., 2002: - Four decades of radioecological research on the Danube river: a reliable basis for protecting the freshwater resources of central Europe of tomorrow, Arsenal Research, Environment Division, Faradaygasse 3, A1030 Vienna.

[9] PANTELICA, A. I., GEORGESCU, I. I. , OPRICA, M. H. I., BORCIA, C. M. 1999 - "INNA and chemical analysis of water and sediments samoled in 1996 from the Romanian sector of the Danube river, Czechoslovac Journal of Physics, vol. 49 (1999), Suppl. S1. 